\title{
Robotic radical cystectomy: changes in enhanced recovery protocols
}

\author{
Goonewardene $S^{1 *}$, Persad $\mathrm{R}^{2}$ and Gillatt $\mathrm{D}^{3}$ \\ ${ }^{1}$ Guys and St Thomas Hospitals, Westminster Bridge Rd, London SE1 7EH, United Kingdom \\ ${ }^{2}$ North Bristol NHS Trust, London, United Kingdom \\ ${ }^{3}$ McQuarrie University, Sydney NSW 2109, Australia
}

Radical cystectomy with urinary diversion is one of the most complex urologic procedures [1,2]. Despite improvements in surgical technique, anaesthesia and perioperative care, radical cystectomy is still associated with significant morbidity and prolonged in-patient stay after surgery $[3,4]$. Fast-track principles are standard procedure in radical cystectomy, to minimise complications. Robotic surgery has been performed in an effort to reduce surgical stress and decrease perioperative morbidity [5]. Despite the degree of dissection, it remains the gold standard for muscle invasive bladder cancer. The magnitude of the surgical insult is associated with the degree of stress response, particularly in ageing patients with multiple comorbidities [2]. However, there has been a growing trend towards Enhanced Recovery Protocols (ERP).

Enhanced recovery protocols are multimodal perioperative care pathways designed to achieve early recovery after surgical procedures by maintaining preoperative organ function and reducing the stress response following surgery [6]. The key elements of ERP include preoperative counselling, optimization of nutrition, standardized analgesic and anaesthetic regimens and early mobilization [6]. These also have the advantage of not compromising patient outcomes [7]. However, guidelines for perioperative care after open radical cystectomy for bladder cancer were recently published, but these recommendations may differ when considering a robotic approach [5]. Some protocols, have gone as far as incorporating re-operative education, expectation setting, prehabilitation, nutrition evaluation, carbohydrate loading, venous thrombosis prophylaxis, normothermia maintenance, local anesthesia, no nasogastric tubes or bowel prep, early feeding, and opioid avoidance [7,8]. Part of this involves enhanced mobilization [9]. No single intervention significantly reduces morbidity, but the combination of many interventions at all levels of the pathway is likely to accelerate the patient journey from diagnosis to return to normal function [2]. As a result, both readmission and complications rate are reduced.

The enhanced recovery patients have shorter time to GI function and recover more quickly then patients not put through enhanced recovery [3]. This protocol clearly improves clinical outcomes in terms of faster return of bowel function and reduction of readmission within 30 days [3]. These also clearly allow limitation of complications and length of stay [4]. A shorter time to stable health status with no increase of complications [6].

In contrast, in some cases, enhanced recovery may also have its' readmission rates- incidence of readmission after radical cystectomy still remains relevant, affecting more than $25 \%$ of patients, mostly affected by urinary tract infections [10]. Multi-institutional studies would be helpful to externally validate these.

In conclusion, ERP is a safe approach promoting standardization of post-operative care and resulting in decreased length of stay and decreased variability [11]. Incorporating minimal access surgery within an established and continuously evolving care pathway is central to continuously improving care [12]. Early nasogastric tube removal reduced morbidity, bowel recovery time and length of hospital stay [13]. Doppler-guided fluid administration allowed for reduced morbidity [13]. A quicker bowel recovery was observed with a multimodal prevention of ileus, including gum chewing and minimally invasive surgery [13].

\section{References}

1. Preston MA, Lerner SP, Kibel AS (2015) New trends in the surgical management of invasive bladder cancer. Hematol Oncol Clin North Am 29: 253-269, viii. [Crossref]

2. Smith J, Pruthi RS, McGrath J (2014) Enhanced recovery programmes for patients undergoing radical cystectomy. Nat Rev Urol 11: 437-444. [Crossref]

3. Persson B, Carringer M, Andrén O, Andersson SO, Carlsson J, et al. (2015) Initial experiences with the enhanced recovery after surgery (ERAS) protocol in open radical cystectomy. Scand J Urol 49: 302-307. [Crossref]

4. McCombie S, Nack T, Willmott J, Hayne D (2015) The development of a radica cystectomy enhanced recovery pathway at fremantle hospital. BJU International 115 : 98-99.

5. Adding C, Collins JW, Laurin O, Hosseini A, Wiklund NP (2015) Enhanced recovery protocols (ERP) in robotic cystectomy surgery. Review of current status and trends. Curr Urol Rep 16: 32. [Crossref]

6. Porpiglia F, Calza E, Poggio M, Fiori C, Cattaneo G, et al. (2015) "Enhanced" recovery program in patients undergoing radical cystectomy: Our experience. European Urology, Supplements 14: e434.

7. Kukreja JB, Kiernan M, Schempp B, Hontar A, Ghazi A, et al. (2015) Cystectomy enhanced recovery pathway: Reduction in length of stay without increased morbidity or readmissions. Journal of Urology 1: e813-e814.

8. Xu W, Daneshmand S, Bazargani ST, Cai J, Miranda G, et al. (2015) Postoperative Pain Management after Radical Cystectomy: Comparing Traditional versus Enhanced Recovery Protocol Pathway. J Urol 194: 1209-1213. [Crossref]

Correspondence to: Goonewardene SS, The Royal Free Hospital, Pond St, London NW3 2NQ, United Kingdom, E-mail: ssg7727@yahoo.co.uk

Key words: robotic surgery, cystectomy, enhanced recovery

Received: January 04, 2016; Accepted: January 27, 2016; Published: January 30, 2016 
9. Jensen BT, Petersen AK, Jensen JB, Laustsen S, Borre M (2015) Efficacy of a multiprofessional rehabilitation programme in radical cystectomy pathways: a prospective randomized controlled trial. Scand J Urol 49: 133-141. [Crossref]

10. Altobelli E, Buscarini M, Gill H, Skinner E (2015) Readmission rate after radical cystectomy in patients managed following the enhanced recovery after surgery protocols. Journal of Urology 1: e855-e856.
11. Lim YW, Cheng C, Lee LS (2015) ERAS enhances perioperative outcomes after open radical cystectomy for bladder cancer. BJU International 115: 23.

12. Campain N, McGrath J, Jackson L, Batchelor N, Daugherty M, et al. (2014) The robot alone is not enough-how to TO provide a comprehensive enhanced recovery service. European Urology, Supplements 13: 14-15.

13. Cerantola Y, Valerio M, Persson B, Jichlinski P, Ljungqvist O, et al. (2013) Guidelines for perioperative care after radical cystectomy for bladder cancer: Enhanced Recovery After Surgery (ERAS( $(\mathbb{R})$ ) society recommendations. Clin Nutr 32: 879-887. [Crossref]

Copyright: (C2016 Goonewardene SS. This is an open-access article distributed under the terms of the Creative Commons Attribution License, which permits unrestricted use, distribution, and reproduction in any medium, provided the original author and source are credited. 